\title{
Treatment in hospital for alcohol-dependent patients decreases attentional bias
}

This article was published in the following Dove Press journal:

Neuropsychiatric Disease and Treatment

29 May 2013

Number of times this article has been viewed

\author{
Valentin Flaudias ${ }^{1,2}$ \\ Georges Brousse 1,2 \\ Ingrid de Chazeron ${ }^{1,2}$ \\ François Planche ${ }^{2}$ \\ Julien Brun ${ }^{2}$ \\ Pierre-Michel Llorca ${ }^{1,2}$ \\ 'Clermont Université, EA 7280 NPsy- \\ Sydo, Clermont-Ferrand, France; ${ }^{2}$ Pôle \\ Psychiatrie B, CHU Gabriel-Montpied, \\ Clermont-Ferrand, France
}

Background and objectives: Previous studies in alcohol-dependent patients have shown an attentional bias $(\mathrm{AB})$ under related substance cues, which can lead to relapse. This $\mathrm{AB}$ can be evaluated by the alcohol Stroop test (AST). The AST is a modified Stroop task in which participants have to name the color of an alcohol-related word or a neutral word. AB is the response-time difference between these two types of words. The goal of the current study was to examine modification of $\mathrm{AB}$ during specialized hospitalization for alcohol dependence, with the suppression of a training bias that could be present in within-subject design.

Methods: Individuals with alcohol-dependence disorders (Diagnostic and Statistical Manual of Mental Disorders, 4th edition) and admitted for withdrawal in the addiction unit of the University Hospital of Clermont-Ferrand (test group, $n=42$ ) and persons with no alcohol or psychiatric disorder (control group, $\mathrm{n}=16$ ), recruited among colleagues and friends of the staff, performed the AST. A subgroup of the test group performed the AST in admission (admission group, $\mathrm{n}=19$ ), and another subgroup undertook the test immediately before discharge (discharge group, $\mathrm{n}=23$ ).

Results: Results showed an $\mathrm{AB}$ only for patients seen at admission $(F[1,55]=3.283, P=0.075)$. Moreover, we observed that the $\mathrm{AB}$ in the admission group (mean $=34 \mathrm{~ms}$, standard deviation $[\mathrm{SD}]=70.06)$ was greater than the $\mathrm{AB}$ in the control group (mean $=23 \mathrm{~ms}, \mathrm{SD}=93.42$ ), itself greater than the $\mathrm{AB}$ in the discharge group (mean $=-12 \mathrm{~ms}, \mathrm{SD}=93.55)(t[55]=-1.71$; $P=0.09$ ).

Conclusion: Although the results are preliminary, the present study provides evidence for changes in the $\mathrm{AB}$ during alcohol-addiction treatment and for the value of these methods to diminish $\mathrm{AB}$ during detoxification.

Keywords: alcohol Stroop test, addiction, attentional bias

\section{Introduction}

Alcohol is regularly consumed by $20 \%$ of French adults, and more than 6.4 million French people consume it daily. ${ }^{1}$ Alcohol is responsible for 33,000 deaths per year in France ${ }^{2}$ and comorbidity with psychiatric disorders is important. ${ }^{3}$ Alcohol abuse and dependence lead to somatic, psychological, family, social, professional, and financial disruption. ${ }^{4,5}$

Dependent patients have a special link with the substance, with an inability to refrain from it (according to Diagnostic and Statistical Manual of Mental Disorders, 4th edition [DSM-IV] criteria). ${ }^{6}$ Therapeutic strategies for alcohol dependence are based on acute treatment (withdrawal) and long-term rehabilitation. ${ }^{7}$ After withdrawal, relapse prevention is the major challenge for the treatment of this disease.
Correspondence: Valentin Flaudias Pôle Psychiatrie B, CHU GabrielMontpied, 58 Rue Montalembert, Clermont-Ferrand 63000, France Tel +33473752072

Email vflaudias@chu-clermontferrand.fr 
Usually, two approaches are combined: psychotherapy and pharmacotherapy. ${ }^{7}$ Recently, new psychotherapeutic approaches developed to improve cognitive impairments described in mental illnesses (eg, schizophrenia or bipolar disorder) have been used in the treatment of addictions. ${ }^{8}$

The functioning of the brain of an addicted patient may differ from that of a nonaddict. ${ }^{9}$ A dependent subject no longer has full control of their external environment. This lack of control led to the observation that substance-related stimuli (ie, the word "alcohol" for an alcohol-dependent patient) induced strong activation compared with non-substancerelated stimuli. This activation results in an attentional bias (AB) in which the attentional system is not able to filter correctly the external information. AB can also be defined as "a phenomenon whereby attentional channeling is directed toward personally valued stimuli, despite an individual's efforts to ignore them."10,11 Thus, AB would be strongly associated with relapse, and in particular with craving. ${ }^{12}$ Development and an increase in craving are influenced by the excess of attention to substance cues. ${ }^{13}$ Thus, craving and AB are highly correlated. ${ }^{10,14-16}$

The evaluation of $\mathrm{AB}$ at the end of hospitalization is evident: several authors have shown that this can predict the likelihood of relapse and therefore the effectiveness of the treatment. ${ }^{10}$ Indeed, Cox et al ${ }^{17}$ observed that after 4 weeks of hospitalization, patients who had a greater AB had an increased risk of relapse compared with those who had a lower AB.

One purpose of a support intervention is thus to reduce AB. The most used tool to show AB in the case of psychological disorders is a modified Stroop task. ${ }^{11}$ The classic Stroop $\operatorname{task}^{18}$ is used in clinical practice to highlight attentional deficits. In this task, participants are instructed to name the color of the ink used to write a word, eg, red, when the word "door" is written in red. In 1935, Stroop showed in one of the conditions of his study that participants required more time to name the color when the word itself was an incongruent color (for example, "blue" written in red) than when it was a congruent color ("blue" written in blue). This task measures the participant's ability to ignore irrelevant stimuli (the meaning of the word) and to focus on the relevant stimulus (the color of the word). The more the stimulus is semantically close to the color name, the more ignoring it is difficult. ${ }^{19}$

The emotional Stroop task is a modification of the original to highlight a lack of attention related to an emotional concept (for review, see Williams et al). ${ }^{11}$ In an emotional Stroop task, Stroop interference is achieved by words emotionally relevant for the participant. For patients with anxiety disorders, the time to name the color of the word is longer when the word is related to the concept of anxiety than when the word is neutral. In patients with post-traumatic stress disorder, this effect is especially marked when the selected words refer to the traumatic event. This interference would be a cue that the patient filters information in an inappropriate way. In this case, the concept linked to the disorder is active and present in memory automatically, and too much attention is allocated to this information. ${ }^{20}$ The result is then a longer processing time to treat another feature of the stimulus - the color.

In the alcohol Stroop test (AST; recently reviewed), ${ }^{10}$ stimuli are alcohol-related words. An AB towards alcohol is noticeable when participants require more time to name the color of an alcohol-related word than for a neutral word. Cox et $\mathrm{al}^{17}$ showed that patients at admission to inpatient treatment have a greater $\mathrm{AB}$ than a group of nonabusers, who themselves have a greater AB than patients in discharge after 4 weeks of treatment.

Our study was designed to evaluate the efficacy of hospital care on the modification of AB. For this, we compared the $\mathrm{AB}$ score in alcohol-dependent admission to inpatient treatment in the French version of the AST. We expected to observe results similar to those of previous studies: ${ }^{17}$ patients at admission should have a greater $\mathrm{AB}$ than nonabusers, whose AB should be greater than patients at discharge. The classic Stroop effect, measuring the general capacity of attention, should not be significantly different between these three groups, indicating that the reduction in attention bias is not due to an increase in attentional capacities. Cox et al ${ }^{17}$ used a within-subjects design, which could be a problematic method because the second measure of $A B$ could just reflect a learning process. We chose to use a between-subjects design, also indicating that the reduction in $\mathrm{AB}$ is not due to a learning process.

\section{Methods \\ Participants}

The test group was composed of alcohol-dependent participants who were recruited from the University Hospital Gabriel-Montpied in Clermont-Ferrand, and more specifically the ward devoted to the treatment of addictive disorders. All subjects were evaluated and diagnosed as dependent by a senior addiction specialist with extensive clinical experience (FP), using DSM-IV criteria.

One subgroup of the test group, the admission group, was composed of patients included during the 4 days after their admission, and another subgroup, the discharge group, was composed of patients included immediately prior to 
discharge, approximately 4 weeks after their admission. The control group consisted of healthy volunteers who had never presented addictive, neurological, or psychiatric disorders. They were unaware of the objectives of the study.

All participants had normal or corrected-to-normal color vision. They were French, and had no language disorders. All participants gave written informed consent to participate in this study, as required by the local ethical committee. Finally, all patients in the test group had undergone standard oxazepam treatment (see Table 1).

\section{Measures}

Stimuli consisted of four neutral words: "robe" (dress), "pont" (bridge), train, and studio; four words semantically related to the notion of alcohol: "alcool" (alcohol), Ricard, "vin" (wine), and whisky; and four color names: "rouge" (red), "jaune" (yellow), "bleu" (blue), and "vert" (green). Stimuli were individually presented in lowercase letters in Courier New font, 72-point bold, centered on the screen. On average, a word covered a visual angle of $3^{\circ}$ broad and height $0.9^{\circ}$. There were three different blocks: one for the neutral words, one for the words for colors, and one for words related to alcohol. The color words were always presented in an incongruent way (eg, "red" appeared only in green, blue, or yellow). In addition, an analysis of the objective frequencies of the words from the French lexical database Lexique $3^{21}$ showed no significant difference between alcohol-related words with the exception of the word Ricard, which was not contained in this base, and neutral words $(t[5]=-0.96$, $P=0.38)$, and color words and neutral words $(t[6]=-0.4$, $P=0.71)$.

\section{Procedure}

The experiment was conducted in a quiet room for nonabuser participants and in patients' hospital rooms. Following the reading of consent, they were informed that the study measured their perception of color.

Participants were installed at a computer. The presentation of stimuli and recording of response times were managed and measured to the nearest millisecond by the DMDX program. ${ }^{22}$ The response times were recorded by a microphone on the PC. The choice of a verbal response was preferred to the choice of a manual response. Manual response offers worse Stroop interference, ${ }^{23}$ and it remains less natural, because it requires a learning phase. The participants were seated about $50 \mathrm{~cm}$ from the screen. They were instructed to concentrate on the fixation cross (+) for $500 \mathrm{~ms}$ before it was replaced by the word. They were to name the color of the word, and they were reminded to respond as quickly as possible, and without error.

As recommended, ${ }^{24}$ stimuli were presented in blocks to avoid the cognitive influence of the item "alcohol" being carried over to the following item. The experiment began with a set of two practice blocks. In the first, the words were replaced by a series of Xs (eg, XXXXX). Participants had to name the colors (ten in total). This step allowed detection of possible color-perception problems or problems related to poor microphone detection. The second practice phase was the presentation of neutral words, not used in the rest of the study ("voiture" [car], "fauteuil" [chair], "route" [road], "télévision" [television], and "chaussure" [shoe]) (in total, ten items).

Finally, the three blocks were presented in random order between participants, with a pause of a few seconds between each block. In total, except for practice items, each participant saw 72 items. The words were presented in three different colors, twice for each block.

\section{Statistical analyses}

The average response time given by item for each block of correct answers was analyzed. Responses less than $300 \mathrm{~ms}$ and more than $1500 \mathrm{~ms}$ were excluded from analyses (less than $1 \%$ of data). The tests were first made on the words semantically related to alcohol, compared with neutral words, then on the color words compared with neutral words, using SPSS 19 (IBM, Armonk, NY, USA). A ShapiroWilk test on the two principal variables (Alcohol Stroop interference and Classical Stroop interference) indicated that these two variables were normally distributed $(P=0.37$ for Alcohol Stroop interference and $P=0.097$ for classical Stroop interference).

Two types of analysis were undertaken, with a repeatedmeasures plan of $2 \times 3$ with type of stimulus (color words or alcohol-related words vs neutral words) and the status of the participant (nonabusers vs admitted patient vs discharged patients). We conducted contrast analysis to assess the intensity of the Stroop effect (classic and alcohol) in different groups of patients and controls. In addition, we undertook comparisons for each type of participant with a Bonferroni adjustment on this data. Response latencies and error proportions are presented in Table 2.

\section{Results \\ Population description}

Forty-two patients were recruited to the test group. Nineteen comprised the admission group, and 23 comprised the 
discharge group. Sixteen participants made up the control group. All characteristics of the population are listed in Table 1. There was no difference between groups on the basis of age or sex $\left(F_{S}<1\right)$.

\section{Alcohol-related words compared with neutral words}

This response-time analysis revealed an effect of type of stimulus $(F[1,55]=5.752, P<0.05)$ and an effect of status of the participant $(F[2,55]=4.25, P<0.05)$. The interaction between these two factors was not significant $(F<1)$ (Figure 1).

To analyze these specific results, we conducted a linear contrast analysis on the AST. This showed a trend effect of status of the participant $(t[55]=-1.714, P=0.092)$, indicating that patients on admission had an alcohol Stroop effect greater than the nonabusers, who themselves had a higher effect than discharged patients. Orthogonal contrasts centered on this linear contrast were not significant $(t[55]=1.174, P=0.246)$.

Planned comparisons showed that patients in admission had a tendency towards an alcohol Stroop effect (34 ms, $F[1,55]=3.283, P=0.075)$ while nonabusers and discharged patients did not have this alcohol Stroop effect (respectively, $23 \mathrm{~ms}, F[1,55]=1.252, P=0.268$ and $12 \mathrm{~ms}$, $F[1,55]=1.552, P=0.218)$.

The mixed model on error-proportions analysis did not show any effect of type of stimulus or status of the participant, and these two factors had no interactions.

\section{Color words compared with neutral words}

The response-time analysis revealed a type of stimulus effect $(F[1,55]=43.53, P<0.001)$, indicating that response times to the color words were generally greater than for neutral words. The analysis also revealed an effect of status of the participant $(F[2,55]=6.164, P<0.05)$, indicating that the response times were different from nonabusers, patients at admission, or those at discharge. The interaction between these two factors was not significant $(F[2,55]=1.343, P=0.269)$.

Table I Sex and age of participants in this study

\begin{tabular}{|c|c|c|c|c|c|c|c|}
\hline & \multirow[t]{2}{*}{$\mathbf{n}$} & \multicolumn{2}{|l|}{ Sex } & \multicolumn{4}{|c|}{ Age (years) } \\
\hline & & Men & Women & Mean & Min & Max & SD \\
\hline $\begin{array}{l}\text { Patients at } \\
\text { admission }\end{array}$ & 19 & 15 & 4 & 46.11 & 27 & 66 & 9.95 \\
\hline Nonabusers & 16 & 14 & 2 & 43.19 & 23 & 58 & 11.49 \\
\hline $\begin{array}{l}\text { Discharged } \\
\text { patients }\end{array}$ & 23 & 18 & 5 & 45.83 & 27 & 60 & 8 \\
\hline
\end{tabular}

Abbreviation: SD, standard deviation.
We conducted a linear contrast analysis on these data. This did not show any effect of status of the participant $(t[55]=1.393, P=0.169)$ on the Stroop effect, indicating that there was no difference between the participants on the classic Stroop effect.

Planned comparisons showed a classic Stroop effect for all participants: $127 \mathrm{~ms}$ at admission $(F[1,55]=25.096$, $P<0.001)$, $92 \mathrm{~ms}$ for nonabusers $(F[1,55=11.178, P<0.001]$, and $76 \mathrm{~ms}$ for discharged patients $(F[1,55]=9.497$, $P<0.01)$.

We found no effect of type of stimulus on error proportions $(F<1)$, but status of the participant had an effect on error proportions $(F[2,55]=3.723, P<0.05)$, and there was interaction between these two factors $(F[2,55]=3.134$, $P=0.05)$. Planned comparisons showed that only patients on admission had a difference in error proportions $(F[2,55]=$ 5.63, $P<0.05)$.

\section{Discussion}

Our results on $\mathrm{AB}$ measured with a French version of the AST showed a trend difference between our three groups of participants: AB was greater in patients on admission, whose $\mathrm{AB}$ was greater than that of nonabusers, who had a greater $\mathrm{AB}$ than that observed in discharged patients. These results suggest an improvement in cognitive performances against related-substance cues in the treatment period.

In spite of low statistical power, these results are consistent with those reported in the literature. ${ }^{17}$ While we observed a decrease in the classic Stroop effect on response times, it did not differ significantly between the different types of participant. This seems to indicate that the observed decrease in $\mathrm{AB}$ was not completely due to a better attentional process, nor to an effect of the attentional process of the oxazepam treatment, which is in accordance with the literature. ${ }^{17}$ Our results show that hospital care leads to reduced AB in alcohol-dependent patients. Our results had the same pattern as those of Cox et al, ${ }^{17}$ who used a within-subjects design. A between-subjects design could be problematic for drawing conclusions, because it is difficult to be sure that there was no other factor of difference between the two groups. Our results, viewed together with previous results, seem to indicate that diminution of $\mathrm{AB}$ was not due to a training bias and that the difference observed between patients at admission and at discharge could be observed with the two types of design.

Williams et $\mathrm{a}^{11}$ have shown that the subjective frequency of items has an influence on the Stroop task. The more frequently a word is encountered by an individual, the more it 
Table 2 Latencies of correct answers (in milliseconds), proportions of errors, and standard deviation (in parentheses) presented by type of stimulus (color words, alcohol-related words vs neutral words) and status of the participant (nonabusers vs patients at admission vs discharged patients)

\begin{tabular}{|c|c|c|c|c|c|c|}
\hline & \multicolumn{2}{|c|}{ Discharged patients } & \multicolumn{2}{|c|}{ Nonabusers } & \multicolumn{2}{|c|}{ Patients at admission } \\
\hline & Latencies & $\%$ ER & Latencies & $\%$ ER & Latencies & \% ER \\
\hline Color words & $1140(125)$ & 1.41 & $1010(111)$ & 1.41 & $1212(202)$ & 9.89 \\
\hline Alcohol-associated words & $1052(178)$ & 6.19 & $94 \mid(I 5 I)$ & 2.19 & $1119(205)$ & 6.82 \\
\hline Neutral words & $1064(197)$ & 4.59 & $918(132)$ & 2.03 & $1085(190)$ & 5.53 \\
\hline \multicolumn{7}{|l|}{ Difference } \\
\hline $\begin{array}{l}\text { Color words - neutral words } \\
\text { (the classic Stroop effect) }\end{array}$ & $76 \mathrm{~ms}^{* *}$ & & $92 \mathrm{~ms}^{* * *}$ & & $127 \mathrm{~ms}^{* * * *}$ & \\
\hline $\begin{array}{l}\text { Alcohol-associated words - neutral words } \\
\text { (the alcohol Stroop effect) }\end{array}$ & $-12 \mathrm{~ms}^{\mathrm{ns}}$ & & $23 \mathrm{~ms}^{\mathrm{ns}}$ & & $34 \mathrm{~ms}^{*}$ & \\
\hline
\end{tabular}

Notes: $* * * P<0.001$; **P $<0.01 ; * P<0.10$; ${ }^{*} P>0.20$.

Abbreviation: ER, errors.

creates interference. The difference observed between our patients at admission, when they were confronted with many alcohol-related items, and our nonabusers could be explained by this phenomenon, but this seems unlikely, because we also observed a difference between patients at admission and at discharge, patients who could estimate that the subjective frequency of items used was comparable. Cox et al ${ }^{17}$ used the staff in the same unit of addiction treatment as their patients, a group control, to avoid this bias. These authors continued to observe a difference between patients and the control group concerning $\mathrm{AB}$. This suggests that the emotional valence of a word is more important in the emotional Stroop task than the subjective frequency. The $\mathrm{AB}$ reduction in patients between admission and discharge is probably due to a decline in the emotional importance of alcoholrelated words.

This decrease between patients at admission and at discharge is probably an indication of the efficacy of the treatment on this dimension. Indeed, the use of psychotropic drugs (ie, oxazepam) can have an effect on the emotional processing of stimuli. ${ }^{25}$ Thus, the decrease in $\mathrm{AB}$ for discharged patients may be due to decreased emotional perception. Moreover, the cognitive-care services probably encourage the patient to establish a functioning inhibiting process from alcoholrelated cues. Indeed, patients are advised to participate in discussion groups, for psychological education and relapse

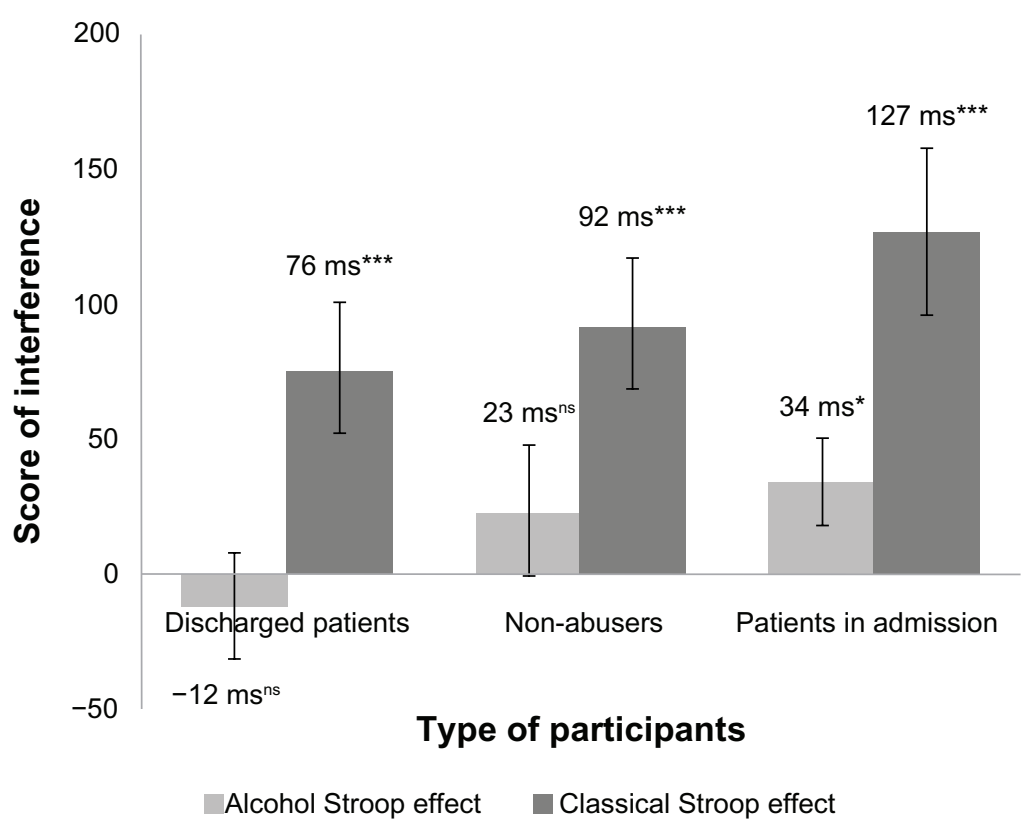

Figure I Classic Stroop effect (difference in response-time average, in milliseconds, for color words and neutral words) and alcohol Stroop effect (difference in responsetime average, in milliseconds, for alcohol-related and neutral words) for each participant group, and associated standard errors. Notes: ${ }^{* * *} P<0.001$; $* * P<0.01$; $* P<0.10$; ${ }^{\text {ns }} P>0.20$. 
prevention, and to engage in individual behavioral and cognitive therapy.

We must nevertheless be careful with these results, due to limitations on use of the Stroop task to explore AB. Indeed, the origins of $\mathrm{AB}$ are actually the subject of debate. This AB could be a problem of initial orientation of spatial attention or a disengagement bias. Phaf and $\mathrm{Kan}^{26}$ showed recently in a review that $\mathrm{AB}$ can occur in short stimulusonset asynchrony (between 50 and $200 \mathrm{~ms}$ ), which favors an initial orientation spatial bias, but also an $\mathrm{AB}$ with long stimulus-onset asynchrony, reflecting a disengagement bias. Field and $\operatorname{Cox}^{10}$ explained that these two processes are involved in AB. Unfortunately, the Stroop task cannot distinguish between these two types of process. ${ }^{27}$ The diminution observed could be attributed to either explanation. It is difficult to determine which process is enhanced by hospital care: initial spatial orientation or the disengagement process. Moreover, the emotional Stroop effect could reflect the fact that emotional stimuli are less readily suppressed or filtered in normal populations, with negative consequences for primary task performance. ${ }^{28}$ Indeed, studies on the emotional Stroop task showed an effect with emotional words in a normal population. ${ }^{29}$ This effect exists in reading, lexical decision, and color naming. ${ }^{30}$ These tasks are all slower with emotional words, and this delay is immune to task-irrelevant variation and to changes in the relative salience of the words and the colors. Further, the delay was absent when emotional and neutral words appeared in a single block, suggesting that the so-called emotional Stroop effect could reflect a stimulus-driven generic slowdown effect rather than a selective-attention mechanism, such as that associated with the classic Stroop effect.

The AST used and developed in this study could indicate the efficacy of the general concept of $\mathrm{AB}$ in the hospital care of a patient, even if it cannot highlight exactly the process involved in this diminution.

At a clinical level, this study and the observation of $\mathrm{AB}$ in a patient population underline the importance of this process in pathology. As mentioned previously, AB is positively correlated with craving and relapse. ${ }^{17}$ These data support the importance of $\mathrm{AB}$ in the maintenance of the disorder.

The Alcohol Attention-Control Training Program developed in a nonaddicted population shows that participants in this program reduce their alcohol consumption and their AB during the following 3 months. ${ }^{31}$ This type of "reducing AB" program could be an interesting topic for treatment of alcohol dependence.

\section{Conclusion and perspectives}

This study, associated with the previous results of a study of $\mathrm{AB}^{17}$ with the AST, shows a diminution of $\mathrm{AB}$ for hospitalized patients. Treatment that works on this AB will probably benefit the patient, and more specifically be associated with a diminution of relapse.

The use of other measures of $\mathrm{AB}$ could be considered to explore in more specific detail which process exactly is enhanced during treatment. An answer to this question could allow us to design a more specific rehabilitation program, and to be more efficient in the hospital care of these patients.

\section{Acknowledgments}

This work was supported by a grant from the Institut de Recherches Scientifiques, Economiques et Sociales sur les Boissons. The authors thank the three anonymous reviewers for their helpful advice, comments, and suggestions on previous drafts of the manuscript. We thank Bruno Pereira too for his assistance concerning statistical analysis.

\section{Disclosure}

The authors report no conflicts of interest in this work.

\section{References}

1. Costes JM. Principales données épidémiologiques concernant les addictions en France. In: Reynaud M, editor. Traité d'addictologie. Paris: Médecine-Sciences Flammarion; 2006.

2. Khazaal Y, Zullino D. Dépendances aux substances et comorbidités psychiatriques: tendances actuelles. Available from: http://guidereha. $\mathrm{ch} /$ sites/default/files/document/file/04_medinfo0902_dependances.pdf. Accessed August 17, 2012.

3. Compton WM, Thomas YF, Stinson FS, Grant BF. Prevalence, correlates, disability, and comorbidity of DSM-IV drug abuse and dependence in the United States: results from the national epidemiologic survey on alcohol and related conditions. Arch Gen Psychiatry. 2007; 64(5):566-576.

4. Heather N. Pleasures and pains of our favorite drug. In: Heather N, Peters TJ, Stockwell TR, editors. Handbook of Alcohol Dependence and Related Problems. New York: Wiley; 2001:5-14.

5. Schall M, Kemeny A, Maltzman I. Factors associated with alcohol use in university students. J Stud Alcohol. 1992;53(2):122-136.

6. American Psychiatric Association. Diagnostic and Statistical Manual of Mental Disorders, 4th ed. Washington: American Psychiatric Association; 1994.

7. Mann K, Hermann D. Individualised treatment in alcohol-dependent patients. Eur Arch Psychiatry Clin Neurosci. 2010;260 Suppl 2: S116-S120.

8. Vocci FJ. Cognitive remediation in the treatment of stimulant abuse disorders: a research agenda. Exp Clin Psychopharmacol. 2008; 16(6):484-497.

9. Volkow ND. The addicted human brain: insights from imaging studies. J Clin Invest. 2003;111(10):1444-1451.

10. Field M, Cox W. Attentional bias in addictive behaviors: a review of its development, causes, and consequences. Drug Alcohol Depend. 2008; 97(1-2):1-20.

11. Williams JMG, Mathews A, MacLeod C. The emotional Stroop task and psychopathology. Psychol Bull. 1996;120(1):3-24. 
12. Anton RF. What is craving? Models and implications for treatment. Alcohol Res Health. 1999;23(3):165-173.

13. Field M, Eastwood B. Experimental manipulation of attentional bias increases the motivation to drink alcohol. Psychopharmacology. 2005; 183(3):350-357.

14. Field M, Christiansen P, Cole J, Goudie A. Delay discounting and the alcohol Stroop in heavy drinking adolescents. Addiction. 2007; 102(4):579-586.

15. Field M. Craving and cognitive biases for alcohol cues in social drinkers. Alcohol Alcohol. 2005;40(6):504-510.

16. Sayette MA, Hufford MR. Effects of cue exposure and deprivation on cognitive resources in smokers. J Abnorm Psychol. 1994;103(4): 812-818.

17. Cox WM, Hogan LM, Kristian MR, Race JH. Alcohol attentional bias as a predictor of alcohol abusers' treatment outcome. Drug Alcohol Depend. 2002;68(3):237-243.

18. Stroop JR. Studies of interference in serial verbal reactions. J Exp Psychol Gen. 1935;121(1):15-23.

19. Neely JH, Kahan TA. Is semantic activation automatic? A critical re-evaluation. In: Roediger HL 3rd, Nairne JS, Neath I, Surprenant AM, editors. The Nature of Remembering: Essays in Honor of Robert G. Crowder. Washington: American Psychological Association; 2001: 69-93.

20. Peretti CS. Anxiety and cognition disorders. Encephale. 1998;24(3): 256-259. French.

21. New B, Pallier C, Brysbaert M, Ferrand L. Lexique 2: a new French lexical database. Behav Res Methods Instrum Comput. 2004;36(3): 516-524.
22. Forster KI, Forster JC. DMDX: a Windows display program with millisecond accuracy. Behav Res Methods Instrum Comput. 2003;35(1):116-124.

23. MacLeod CM. Half a century of research on the Stroop effect: an integrative review. Psychol Bull. 1991;109(2):163-203.

24. Cox WM, Fadardi JS, Pothos EM. The addiction-Stroop test: theoretical considerations and procedural recommendations. Psychol Bull. 2006; 132(3):443-476.

25. Fouks L, Pinalie B, Porcheron JB, Cardon A. The clinical activity of oxazepam. Acta Psychiatr Scand. 1978;58(S274):99-103.

26. Phaf RH, Kan KJ. The automaticity of emotional Stroop: a metaanalysis. J Behav Ther Exp Psychiatry. 2007;38(2):184-199.

27. MacLeod C, Mathews A, Tata P. Attentional bias in emotional disorders. J Abnorm Psychol. 1986;95(1):15-20.

28. Yiend J. The effects of emotion on attention: a review of attentional processing of emotional information. Cogn Emot. 2010;24(1):3-47.

29. Kahan TA, Hely CD. The role of valence and frequency in the emotional Stroop task. Psychon Bull Rev. 2008;15(5):956-960.

30. Algom D, Chajut E, Lev S. A rational look at the emotional Stroop phenomenon: a generic slowdown, not a Stroop effect. J Exp Psychol Gen. 2004;133(3):323-338.

31. Fadardi JS, Cox WM. Reversing the sequence: reducing alcohol consumption by overcoming alcohol attentional bias. Drug Alcohol Depend. 2009;101(3):137-145
Neuropsychiatric Disease and Treatment

\section{Publish your work in this journal}

Neuropsychiatric Disease and Treatment is an international, peerreviewed journal of clinical therapeutics and pharmacology focusing on concise rapid reporting of clinical or pre-clinical studies on a range of neuropsychiatric and neurological disorders. This journa is indexed on PubMed Central, the 'PsycINFO' database and CAS

\section{Dovepress}

The manuscript management system is completely online and includes a very quick and fair peer-review system, which is all easy to use. Visit http://www.dovepress.com/testimonials.php to read real quotes from published authors. 